УДК 574.21

БИОЛОГИЧЕСКИЙ МОНИТОРИНГ МАЛЫХ РЕК

Кубрина Л.В.

ФГБОУ ВО «Омский государственный педагогический университет», Омск, e-mail: kubrina-lyudmila@mail.ru

На современном этапе развития общества антропогенная нагрузка оказывает существенное воздействие на экосистемы. Высокий уровень загрязнения окружающей среды тяжелыми металлами может превысить адаптационные возможности живых организмов и способен повлечь за собой метаболический регресс. Важнейшей составной частью экологического мониторинга окружающей природной среды является биомониторинг - система наблюдений, оценки и прогноза различных изменений в биоте, вызванных факторами антропогенного происхождения. Биомониторинг делает возможной прямую оценку качества среды и является одним из уровней последовательного процесса изучения здоровья экосистемы. В рамках нашей статьи мы провели исследование, которое было направлено на изучение влияния воды из реки Омь, набранной в разное время и в различных местах на территории г. Омска и его окрестностей, на всхожесть семян редиса. Наименьшая всхожесть наблюдается на участке возле Любинского моста в весенний период - 81,1\%, чуть больше всхожесть в осенний период $-85.5 \%$. Пробы с контрольным вариантом у семян редиса показали $90.1 \%$, участок между 17 и 18 линиями - 86.6\%. Результат Степного поселка составил 81,7. Анализ полученных данных подтверждает воздействие проб реки Омь на прорастание семян редиса.

Ключевые слова: метод, биотест, биоиндикация, биотестирование, токсичность, малые реки

\title{
BIOLOGICAL MONITORING OF SMALL RIVERS
}

Kubrina L.V.

Omsk State Pedagogical University,Omsk, e-mail: kubrina-lyudmila@mail.ru

At the present stage of development of society anthropogenic load has a significant impact on ecosystems. High levels of heavy metal pollution can exceed the adaptive capacity of living organisms and can lead to metabolic regression. The most important component of environmental monitoring of the environment is biomonitoring $-\mathrm{a}$ system of observation, assessment and prediction of various changes in the biota caused by factors of anthropogenic origin. Biomonitoring makes it possible to directly assess the quality of the environment and is one of the levels of the sequential process of studying the health of the ecosystem. As part of our article, we conducted a study that was aimed at studying the influence of water from the river om, recruited in different time frames and in different places in the city of Omsk and its surroundings, on the germination of radish seeds. The lowest germination is observed at the site near the lubinsky bridge in the spring $-81.1 \%$, a little more germination in the autumn $-85.5 \%$. Samples with the control variant in radish seeds showed $90.1 \%$, the area between 17 and 18 lines- $86.6 \%$. The result of the Steppe settlement was 81.7 . The analysis of the obtained data confirms the impact of the om river samples on the germination of radish seeds.

Keywords: method, bioassay, bioindication, bioassay, toxicity, small rivers

Мониторинг и наблюдение за состоянием окружающей природной среды охватывают не только изменения абиотической составляющей живой оболочки, но и ответной реакции биотического компонента, тем самым определяет широкий спектр методов и приемов исследований, которые используются при проведении экологического мониторинга [1].

Естественно, антропогенная нагрузка оказывает существенное воздействие на процесс функционирования водных экосистем.

Загрязнение окружающей среды тяжелыми металлами может превысить адаптационные возможности живых организмов и способно повлечь за собой метаболический регресс [2].

В последние десятилетия резко увеличилось антропогенное воздействие на окружающую среду [3].

Охрана окружающей среды и контроль над уровнем ее загрязнения в городской среде требует привлечения эффективных и недорогостоящих методов изучения природных комплексов. Основные методы анализа (химический и физико-химический) не могут показать все загрязнения, которые находятся на участке.

К таким загрязнениям можно отнести сложные трансформации, образующие токсичные соединения. Поэтому необходимы методы интегральной оценки окружающей среды.

Для определения экологического состояния среды возможно использование методов биомониторинга $[4,5]$. Сюда относятся биоиндикация и биотестирование [4].

Основные методы анализа (химический и физико-химический) не могут показать все загрязнения, которые находятся на участке. К таким загрязнениям можно отнести сложные трансформации, образующие токсичные соединения. Поэтому необходимы методы интегральной оценки окружающей среды. Примером может служить биоиндикация и биотестирование. 
Растения являются одними из основных объектов биоиндикации, так называемой фитоиндикации. В рамках фитоиндикации изучается влияние стрессового воздействия на растения. Для фитоиндикации используются мхи, лишайники, сосудистые растения, хвойные и лиственные породы [6].

Мониторинг и наблюдение за состоянием окружающей природной среды охватывают не только изменения абиотической составляющей живой оболочки, но и ответной реакции биотического компонента, тем самым определяет широкий спектр методов и приемов исследований, которые используются при проведении экологического мониторинга [7].

Цель работы: провести экологическую оценку качества воды из р. Омь в серии биотестов.

Объект исследования: вода р. Омь г. Омска. редис.

Предмет исследования: биоиндикаторы -

\section{Материалы и методы исследования}

В качестве тест-организма может выступать растительный объект-индикатор - редис, обладающий достаточно чувствительной «мишенью». Редис применяется для биотестирования сточных и природных вод, является чувствительным тест-организмом к загрязнению почвы кадмием, цинком, медью и никелем.

Территория Западной части Сибири усеяна многочисленными реками и речками, и среди них выделяется правый приток Иртыша. Эта река называется Омь, в бассейне которой находятся несколько районов Омской области, а также Новосибирской.

Началом Оми принято считать озеро Омское, которое находится в довольно болотистой местности, которая называется Васюганская равнина. Отсюда река спускается по другой низменности - Барабинской, создавая устье около г. Омск. А устье р. Омь в Омске, по правому берегу Иртыша.

Среди главных особенностей реки - ее длина, которая равна 1091 км, и площадь бассейна, имеющий площадь в 52600 км². Склоны долины нечеткие, практически сливаются с местностью. Но такой пейзаж можно наблюдать только на верхних участках реки.

Ниже все меняется - долина становится трапецеидальной, иногда асимметричной. Ширина реки имеет довольно широкий диапазон - от 200 м до 18 км. Склоны по всему течению могут менять свой характер, становясь то пологими, то крутыми, или же очень обрывистыми. Глубина реки 0,3-4,1 м, средняя скорость течения около $0,5 \mathrm{~m} / \mathrm{c}$.
Во многих местах берега используются для сельского хозяйства, поэтому местность распахана и засеяна. Пойма имеет двухсторонний характер, отличаясь заболоченностью, гривами.

Для реки характерны перекаты и плесы, которые отличаются по руслу реки. Вода течет со скоростью от 40 см в секунду - минимум - до 1,4 м в секунду максимум. Питание водоема в основном снеговое - таянием снегов и льда, а также дождями.

Половодье может наступить в мае и закончиться в июле или августе. Вдоль течения реки можно увидеть несколько расширений, которые имеют форму озер. Они соединяются между собой. Но такая особенность встречается в верховьях Оми, а нижняя часть - извилистая, и разветвлений практически не имеет.

Представителей фауны в реке не так и много. Некоторые исчезли совсем, в частности нельма и стерлядь. Сейчас постоянными жителями являются лунь, щука, язь, карась, вьюн. Вдоль берегов растут в основном кустарники.

Расположены три крупных населенных пункта - Омск, Куйбышев и Калачинск. По территории Омской области текут 3 рукава, а по Новосибирской - около 20, длина притоков варьируется от 86 до более 1 тысячи километров. Крупными из них принято считать Ичу, Угурманку, Тарку, Тартас, Узаклу.

По берегам Оми расположены многочисленные деревни, поселки, г. Калачинск и административный центр нашей области, названный по имени этой реки - г. Омск.

Вода ее используется для снабжения населенных пунктов, животноводческих комплексов и орошения земель.

В рамках нашей работы мы провели исследование, которое было направлено на изучение влияния воды из реки Омь в различных ее местах на территории г. Омска и его окрестности, на всхожесть семян редиса.

Водосбор проводился на трех участках г. Омска: осень (2018 г.): возле Любинского моста, участок между 17 и 18 линиями, поселок Степной. Для контроля была использована проточная вода (рис. 1).

Нами было проведено исследование состояния воды химическими, физико-химическими и уровень загрязнения методом биоиндикации. Для физико-химического анализа качества воды применяли: $\mathrm{pH}-$ $150 \mathrm{MИ} \mathrm{с} \mathrm{набором} \mathrm{электродов,} \mathrm{pH}$-метр/иономер ЭКОТЕСТ 120/АТС, кондуктометр HANNA модель DIST 5 и спектрофотометр ПЭ 5300B. 


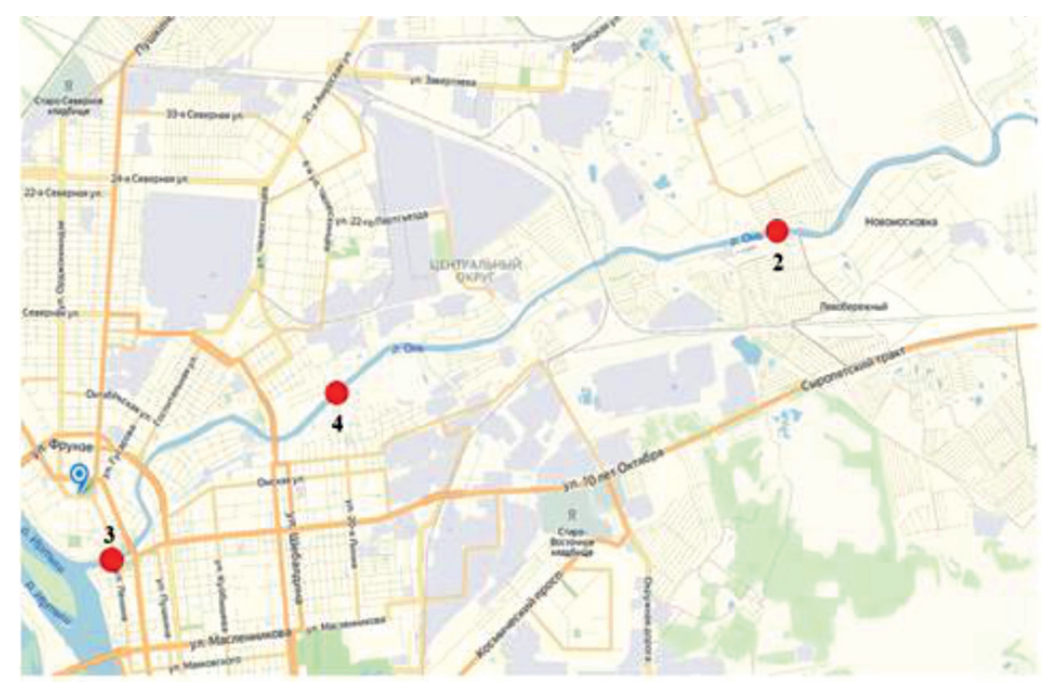

Рис. 1. Участки сбора воды р. Омь г. Омска

Семена растений помещали в чашки Петри с трехкратной повторностью по 30 семян в 5 чашек на каждый участок водосбора.

Закладывались и снимались семена одновременно. При проращивании семян в качестве подстилки использовалась фильтровальная бумага.

Перед проращиванием семян фильтровальную бумагу увлажняли.

Проводились опыты при комнатной температуре $20^{\circ} \mathrm{C}$ и естественном освещении.

На протяжении 6 дней поливали семена водой с разных участков водосбора. Всхожесть и энергия прорастания семян определялись по общепринятым методикам (ГОСТ 12039-82 и ГОСТ 12038-84).

\section{Результаты исследования и их обсуждение}

Химический анализ воды р. Омь представлен в таблице.

На втором участке превышение ПДК по общей жесткости в 12 раз; хлориды в пределе ПДК; сульфаты превышены в 2,5 раза; превышение БПК в 1,5 раза; аммонийного азота в 2 раза; нитритный азот в 0,5 раза.

Содержание ионов железа и кислотность в норме.

На третьем участке превышение ПДК по общей жесткости 12 раз, сульфатам в 2,2 раза, БПК в 0,5 раза и нитритному азоту в 4 раза. Содержание ионов железа и кислотность в норме.
На четвертом участке превышение ПДК по общей жесткости в 14 раз, сульфатам в 2,2 раза, БПК в 0,5 раза и аммонийному азоту в 0,5 раза.

Содержание ионов железа и кислотность в норме.

Все остальные показатели в пределах допустимой концентрации.

Такой анализ показывает, что на протяжении р. Омь, в некоторых ее участках, осуществляется сброс в воду мусора и других бытовых отходов.

Кроме этого подземными водами с мест ТБО происходит вымывание токсических веществ в реку.

Так же важным пунктом является промышленность, сельское хозяйство и автотранспорт, выбросы и стоки которых загрязняют реку.

Полученные экспериментальные данные были подвергнуты статистической обработке с вычислением основных статистических параметров.

Анализ всхожести семян редиса представлен на рис. 2 .

Для сравнения токсического эффекта водных проб с контрольным вариантом (90,0\% всхожесть) было установлено (рис. 2), что наименьшая всхожесть, достоверно отличимая от контроля $(\mathrm{p}<0,001)$, зарегистрирована в варианте $3(80 \%)$.

Наибольшая энергия прорастания и всхожесть, достоверно отличимая от контроля, зарегистрирована в вариантах 3 и 4 (86,0\%; 85,0\% соответственно). 
Химический анализ реки Омь

\begin{tabular}{|c|c|c|c|c|c|}
\hline Показатель & $\begin{array}{c}\text { Единицы } \\
\text { измерения }\end{array}$ & ПДК & 2 & 3 & 4 \\
\hline Общая щелочность (НCOз3) & мГ-эКВ/л & Неуст. & $4,32 \pm 0,12$ & $4,16 \pm 0,29$ & $3,35 \pm 0,10$ \\
\hline Щелочность $\left(\mathrm{CO}_{3}^{2-}\right)$ & $\mathrm{M \Gamma} / \mathrm{дм}^{3}$ & Не уст. & Не обнар. & Не обнар. & Не обнар. \\
\hline Жесткость общая & ммоль/дм ${ }^{3}$ & 0,40 & $5,18 \pm 0,39$ & $5,10 \pm 0,32$ & $6,12 \pm 0,40$ \\
\hline Хлориды & $\mathrm{M \Gamma} / 2 \mathrm{M}^{3}$ & 300,00 & $79,70 \pm 5,03$ & $45,28 \pm 7,06$ & $92,90 \pm 4,20$ \\
\hline Сульфаты & $\mathrm{M \Gamma} / \mathrm{дM}^{3}$ & 100,00 & $242,50 \pm 20,98$ & $216,50 \pm 19,16$ & $221,40 \pm 20,40$ \\
\hline БПК & мг/дм ${ }^{3}$ & 2,00 & $3,28 \pm 0,56$ & $3,01 \pm 0,25$ & $3,04 \pm 0,43$ \\
\hline Азотаммонийный & мг/дм ${ }^{3}$ & 0,40 & $0,72 \pm 0,05$ & $0,39 \pm 0,05$ & $0,78 \pm 0,05$ \\
\hline Азотнитратный (по азоту) & $\mathrm{M \Gamma} / \mathrm{дM}^{3}$ & 9,10 & Не обнар. & Не обнар. & Не обнар. \\
\hline Азотнитритный (по азоту) & $\mathrm{M \Gamma} / \mathrm{дм}^{3}$ & 0,02 & $0,031 \pm 0,008$ & $0,086 \pm 0,013$ & $<0,010$ \\
\hline Ионы железа & мг/дм ${ }^{3}$ & 0,10 & $0,05 \pm 0,01$ & $0,03 \pm 0,01$ & $<0,01$ \\
\hline $\mathrm{pH}$ & ед. $\mathrm{pH}$ & $6,5-8,5$ & $7,57 \pm 0,10$ & $7,84 \pm 0,10$ & $7,87 \pm 0,10$ \\
\hline
\end{tabular}

\section{Всхожесть семян редиса (\%)}

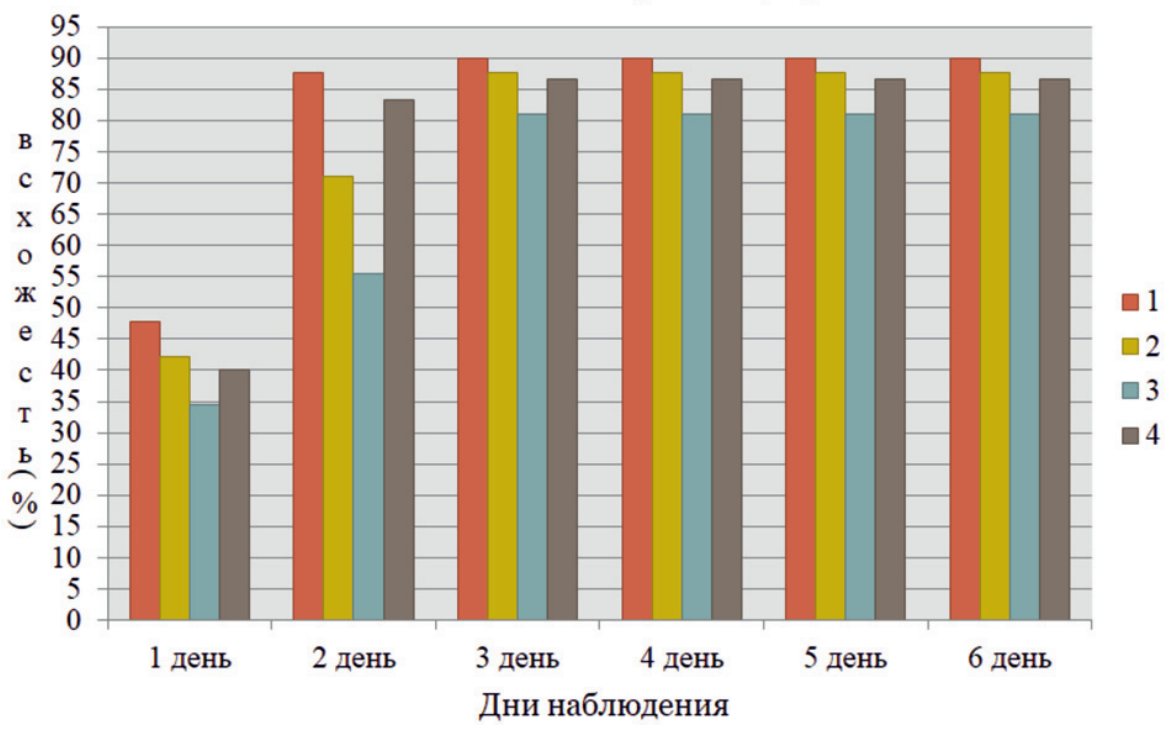

Рис. 2. Всхожесть семян редиса

\section{Выводы}

Проведенные исследования позволили сделать ряд выводов и заключений.

На протяжении реки Омь, в некоторых ее участках, осуществляется сброс в воду мусора и других бытовых отходов. Кроме этого подземными водами с мест ТБО происходит вымывание токсических веществ в реку. Также важным пунктом является промышленность, сельское хозяйство и автотранспорт, выбросы и стоки которых загрязняют реку. Основное влияние на состояние водного источника оказывает антропогенный фактор.
В серии первичного скрининга возможно использовать тест-культуру редис для оценки фитотоксичности и мутагенности, а также за короткий срок получить информацию о генотоксическом эффекте воды и смоделировать более сложные этапы исследования.

\section{Список литературы}

1. Александрова Т.В., Нахаева В.И. Генотоксический анализ водных проб естественного источника питьевой воды из реки Омь на генные и хромосомные мутации // Современные проблемы науки и образования. 2014. № 6. [Электронный ресурс]. URL: https://science-education.ru/ru/article/ view? $\mathrm{id}=15369$ (дата обращения: 17.12.2019). 
1. Тюменцева Е.Ю., Штабнова В.Л. Контроль качества водохозяйственного комплекса как вклад в обеспечение экологической безопасности г. Омска // Вестник Пермского национального исследовательского политехнического университета. Прикладная экология. Урбанистика. 2016. № 2 (22). C. 79-95.

2. Чернова Е.Н., Коженкова С.И. Определение пороговых концентраций металлов в водорослях-индикаторах прибрежных вод северо-западной части Японского моря // Океанология. 2016. Т. 56. № 3. С. 1-10.

3. Кубрина Л.В. Экологическое зонирование техногенных территорий с использованием биоиндикационных индексов // Современное состояние и потенциал развития туризма в России: материалы статей Юбилейной X Между- нар. научн.-практ. конф. Омск: Омский государственный институт сервиса, 2013. С. 186-188.

4. Луговская Л.А. Оценка комфортности среды по флуктуирующей асимметрии дуба черешчатого (Quercusrobur L.) // Научные ведомости. Серия Естественных науки. 2016. № 18 (239). Выпуск 36.87 с.

5. Рунова Е.М., Гнаткович П.С. Экологическая оценка рекреационных зон города Братска методом флуктуирующей асимметрии березы повислой // Фундаментальные исследования. 2013. № 11-2. С. 223-227.

6. Александрова Т.В. Экологическая оценка качества питьевой воды из реки Омь до и после водоподготовки в серии биотестов на токсичность и мутагенность: автореф. ... дис. канд. биол. наук. Омск, 2010. 23 с. 